\title{
Regional Cerebral Blood Flow in the Newborn Beagle Pup: the Germinal Matrix is a "Low-Flow" Structure
}

\author{
JOSEPH F. PASTERNAK, ${ }^{(37)}$ DENNIS R. GROOTHUIS, JOAN M. FISCHER, AND \\ DOLORES P. FISCHER \\ Department of Pediatrics and Division of Neurology, Evanston Hospital, Evanston, Illinois and the Departments of \\ Pediatrics and Neurology, Northwestern University School of Medicine, Evanston, Illinois, USA
}

\begin{abstract}
Summary
The newborn beagle pup serves as a model for neonatal intraventricular hemorrhage (IVH). Fluctuations in germinal matrix blood flow are felt to play a major role in the pathogenesis of IVH. We studied regional cerebral blood flow in awake newborn beagle pups utilizing $\mid{ }^{14} \mathrm{Cl}$-iodoantipyrine as a blood flow indicator and quantitative autoradiography. The equilibrium [tissue]:[blood] partition coefficient for iodoantipyrine was $1.13 \pm .06$ for grey matter. Blood flow was calculated for cerebral cortex (frontal $=59 \pm 9$ $\mathrm{ml} / 100 \mathrm{~g} / \mathrm{min}$ ), 14 subcortical nuclear structures (e.g., caudate $=$ $45 \pm 6 \mathrm{ml} / 100 \mathrm{~g} / \mathrm{min}$ ), 3 white matter structures (centrum semiovale $=7 \pm 1 \mathrm{ml} / 100 \mathrm{~g} / \mathrm{min})$, and germinal matrix $(7 \pm 1 \mathrm{ml} / 100 \mathrm{~g}$ / min) (mean \pm S.E.).

We conclude that under normal physiologic conditions the germinal matrix receives relatively low blood flow. This information can be used for comparison with germinal matrix blood flow during adverse experimental conditions.

\section{Speculation}

wLow baseline blood flow may place the germinal matrix at risk for ischemic injury during hypoxic or hypotensive stress. This ischemic injury may be a critical step in the pathogenesis of intraventricular hemorrhage, either by disrupting vascular integrity or by producing a disproportionate increase in germinal matrix blood flow (luxury perfusion) after reestablishment of normoxemia and normotension.
\end{abstract}

Increasing attention is being focused on the regulation of cerebral blood flow (CBF) in newborn infants. The pathophysiology of both perinatal asphyxia and neonatal intraventricular hemorrhage have been linked to fluctuations in CBF (25). Although quantitative studies of CBF in newborn infants have been performed $(22,24,29,35)$, these results are limited by the poor spatial resolution of the techniques.

Recent advances have made it possible to accurately measure blood flow to small brain regions in unanesthetized animals (18, $19,30)$. We set out to study the regulation of regional blood flow (rCBF) in newborn animals. We utilized the beagle puppy as our experimental animal because the newborn beagle has recently been established as an animal model for neonatal intraventricular hemorrhage $(8,9)$. In this report, we present in detail our methods and $\mathrm{rCBF}$ values for normal, unanesthetized pups.

\section{MATERIALS AND METHODS}

Regional cerebral blood flow (rCBF) was studied in newborn (12-48 h old) purebred beagle pups (Laboratory Research Enterprises, Inc., Kalamazoo, MI) by the methods of Sakurada et al. (30). The pups were lightly anesthetized with nitrous oxide and halothane. Polyethylene catheters filled with 1.0 international units (IU) $\mathrm{Na}$ heparin per $1.0 \mathrm{cc} 0.9 \% \mathrm{NaCl}$ were inserted bilaterally into the femoral arteries and veins via skin incisions. The wounds were infiltrated with $2 \%$ lidocaine jelly (Astra Pharmaceutical Products, Worcester, MA) and the hind quarters of the animal wrapped in a cotton stocking and fast-setting plaster bandage (Johnson and Johnson Co, New Brunswick, NJ). The plaster cast was secured to a lead brick. The animals were able to move their head and forelimbs freely.

The pups were allowed to recover from anesthesia for at least $2 \mathrm{~h}$. Oxygen content of inspired gas was maintained at $30-40 \%$ throughout the recovery period and during the blood flow experiment. Body temperature was monitored continuously via rectal probe and maintained at $36.0-37.5^{\circ} \mathrm{C}$ by radiant heat lamps. Arterial pressure was monitored continuously via one femoral artery catheter. The other femoral artery catheter was cut to a total length of $8 \mathrm{~cm}$ and was connected to the ipsilateral venous catheter with a short $(<1 \mathrm{~cm})$ length of silicon rubber tubing (internal diameter, $1.2 \mathrm{~mm}$, LKB Instruments, Inc., Rockville, MD) (2). Just before the administration of isotope, $0.1 \mathrm{cc}$ arterial blood was removed for determination of arterial gas tensions (Radiometer BM 53 MK2 Blood Micro System, Copenhagen, Denmark). The tracer, $100 \mu \mathrm{Ci}$ of 4 -iodo- $\left(N\right.$-methy)- $\left[{ }^{14} \mathrm{C}\right]$-antipyrine $\left(\left[{ }^{14} \mathrm{C}\right]-\mathrm{IAP}\right.$, specific activity $50-60 \mathrm{mCi} / \mathrm{mmole}$, New England Nuclear, Boston, MA) in $1.0 \mathrm{cc} 0.9 \% \mathrm{NaCl}$, was infused via the remaining venous catheter at a steadily increasing rate utilizing a Harvard variable-rate infusion pump (Harvard Apparatus Co., Inc., South Natick, MA). The [ $\left.{ }^{14} \mathrm{C}\right]$-IAP was previously determined to have $>97 \%$ radiochemical purity by silica gel chromatography (Baker-flux plate, J. T. Baker Chemical Co., Phillipsburg, NY) in benzene/ethyl acetate $(3 / 7, v / v)$. During the infusion, timed arterial samples (5-sec intervals) were obtained by inserting 21 gauge needles attached to $1 \mathrm{cc}$ syringes without plungers into the silicon fistula. The syringes filled spontaneously.

The experiment was terminated by decapitation at $30 \mathrm{sec}$. The brain was rapidly removed, frozen in liquid Freon XII cooled to $-40^{\circ} \mathrm{C}$ and covered with embedding matrix (Lipshaw Manufacturing Co., Detroit, MI). Blood samples were centrifuged and plasma was pipetted into tared scintillation vials. Vials then received $1.0 \mathrm{cc}$ tissue solubilizer (NCS, Amersham Corp., Arlington Hts, IL); $24 \mathrm{~h}$ later $18 \mathrm{cc}$ toluene based fluor (Spectrafluor PPO-POPOP, Amersham Corp.) was added. Radioactivity was measured by liquid scintillation spectroscopy (Packard $300 \mathrm{C}$ Liquid Scintillation Counter, Downers Grove, IL), with appropriate quench corrections. Sample activity was expressed in $\mathrm{nCi} / \mathrm{g}$.

Serial $20-\mu$ thick sections of brain were cut at $-20^{\circ} \mathrm{C}$ with a cryomicrotome (Minot custom microtome, model CTI, International Equipment Corp, Needham Heights, MA). Six consecutive sections were picked up on glass slides and rapidly dried on a slide warmer at $65^{\circ} \mathrm{C}$. Four consecutive sections were used for autoradiography. Adjacent sections before and after those for autora- 
diography were fixed in formalin-ammonium bromide solution (2 $\mathrm{g} \mathrm{NH}_{4} \mathrm{Br} / 100 \mathrm{ml} \mathrm{10 \%} \mathrm{formaldehyde} \mathrm{solution)} \mathrm{and} \mathrm{stained} \mathrm{with}$ hematoxylin-eosin for histologic correlation. The subsequent 44 sections were discarded. This procedure was repeated until the entire brain had been sectioned.

The dried tissue sections were placed in an $\mathrm{x}$-ray film cassette along with $\left[{ }^{14} \mathrm{C}\right]$-methylmethacrylate standards (Amersham Corp) which had been previously calibrated to reference $20-\mu$ thick brain sections of known activity (30). The sections and standards were allowed to expose the film (MR-1, Kodak, Rochester, NY) for 4-8 wk.

Optical density (OD) values were determined from the $x$-ray film with a point densitometer (Macbeth, Newburgh, NY) with a circular aperture of $1 \mathrm{~mm}$ diameter. The location of the autoradiographic image from individual brain areas was identified by overlying the autoradiograph with the adjacent histologic section. Multiple determinations of $O D$ values from each area were obtained; the mean was converted to isotope concentration $(\mathrm{nCi} / \mathrm{g}$ ) by means of a standard curve constructed from the OD values of the $\left[{ }^{14} \mathrm{C}\right]$-methylmethacrylate standards. Blood flow was then calculated according to the formula:

$$
\mathrm{Ci}(\mathrm{T})=\mathrm{F} \int_{0}^{\mathrm{T}} \mathrm{Ca}(\mathrm{t}) \mathrm{e}^{-[\mathrm{F}(\mathrm{T}-\mathrm{t})] / \lambda} d t
$$

where $\mathrm{Ci}(\mathrm{T})$, tissue content of isotope at time $\mathrm{T} ; \lambda$, [tissue]:[blood] equilibrium partition coefficient; $F$, blood flow; and $\mathrm{Ca}(\mathrm{t})$, time dependent arterial concentration of isotope. The [tissue]:[blood] equilibrium partition coefficient was determined in 5 additional animals (24-96 h of age) by the methods outlined by Sakurada et al. (30). For these experiments, animals were anesthetized with nitrous oxide and halothane, tracheotomized, and ventilated with a Harvard small animal ventilator. Femoral arterial and venous catheters were placed. A laparotomy was performed; both renal arteries, superior mesenteric artery, inferior mesenteric artery, hepatic artery, and hepatic vein were identified and ligated. After closure of the abdominal incision, $50 \mu \mathrm{Ci}\left[{ }^{14} \mathrm{C}\right]-\mathrm{IAP}$ in $0.5 \mathrm{cc} 0.9 \%$ $\mathrm{NaCl}$ was given intravenously. Arterial blood samples were obtained at 15, 30, 45, 60, and $90 \mathrm{~min}$. Immediately after the 90-min sample was obtained, the animals were killed by decapitation. The brain was hemisected and multiple samples of brain from cortex, white matter, germinal matrix, deep nuclear structures, and brain stem were obtained from one half. The other half was immediately frozen and processed for histology and autoradiography as described above except that SB-5 film (Kodak) was used. Blood and tissue samples were placed in tared scintillation vials and processed to determine isotope concentration as described above. For each brain area, the [tissue]:[blood] equilibrium partition coefficient $(\lambda)$ was calculated by the formula:

$$
\lambda=\frac{\mathrm{nCi} / \mathrm{g} \text { (tissue) }}{\mathrm{nCi} / \mathrm{g}(90 \text { min blood })}
$$

The [red blood cell]:[plasma] partition coefficient for $\left[{ }^{14} \mathrm{C}\right]$-IAP was determined with the methods of Carlin and Chien (3).

\section{RESULTS}

The [red blood cell]:[plasma] partition coefficient was $0.97 \pm$ .04 (mean \pm S.D.). [Brain tissue]:[blood] partition coefficients were determined in 5 animals. (Fig. 1). In any single animal, the variability in equilibrium isotope concentration (as determined by liquid scintillation counting) for multiple areas scattered throughout the brain was less than $15 \%$. An averaged mean partition coefficient for each animal was calculated using the mean isotope content from at least eight brain regions, including white matter, grey matter and germinal matrix. For the five animals, the averaged mean partition coefficient was $1.14 \pm 0.10$ (mean \pm S.E.). Partition coefficients for discrete brain regions could be calculated using a value for tissue isotope content obtained from the autoradiographs. The equilibrium partition coefficient of IAP was 1.13 \pm 0.06 for grey structures, $1.02 \pm 0.08$ for white matter, and 1.07 \pm 0.08 (mean \pm S.E.) for germinal matrix. For convenience, blood flow to all areas was calculated using a partition coefficient of 1.1.

The physiologic parameters of the animals used to determine blood flow were (mean \pm S.E.): $\mathrm{PO}_{2}, 149 \pm 21 \mathrm{~mm} \mathrm{Hg} ; \mathrm{PCO}_{2}, 33$ $\pm 2 \mathrm{~mm} \mathrm{Hg} ; \mathrm{pH}, 7.41 \pm 0.02$; hematocrit $43 \pm 2 \%$; blood pressure, $59 \pm 6 \mathrm{~mm} \mathrm{Hg}$; and temperature, $36.8 \pm 0.1^{\circ} \mathrm{C}$.

The germinal matrix (GM) was present in the subependymal region throughout the entire extent of the lateral ventricles. It was most prominent at the anterolateral aspect of the lateral ventricle, especially overlying the caudate nucleus (Fig. 2). Blood flow to $\mathrm{GM}$ was low $(7 \pm 1 \mathrm{ml} / 100 \mathrm{~g} / \mathrm{min})$ and was not different from flow to the centrum semiovale. The low GM blood flow sharply contrasted with the considerably higher flows seen in all other cellular areas of brain.

Blood flow to frontal cortex was calculated from sections at the level of the head of the caudate nucleus (Fig. 2). Flow to frontal cortex was consistently, although insignificantly $(P>0.1)$, higher than flow to more posterior cortex. Histologically, the cortex in the newborn dog does not have a uniform neuronal density. The uppermost cortical layers are more compact, reflecting incomplete migration of neurons and production of neuropile. A similar gradient of isotope uptake was seen in corresponding autoradiograph, implying that the more compact layers received higher flow than the less compact lower cortical layers. The cortical flow values reported here represent average values for the entire cortical thickness. Highest flows were seen in grey structures of the posterior circulation, especially posterior thalamus, oculomotor nuclei, inferior olives, and pontine reticular formation. Blood flow values are summarized in Table 1.

\section{DISCUSSION}

Carlin and Chien (3) found that the [red blood cell]:[plasma] partition coefficient for iodoantipyrine was $0.97 \pm .03$ for adult dogs. Our value for newborn puppies, $0.97 \pm .04$ (mean \pm S.D.), is essentially identical. This result was convenient for two reasons. First, if the [red blood cell]:[plasma] partition coefficient differs significantly from unity, the [brain tissue]:[blood] partition coefficient $(\lambda)$ varies with hematocrit and the calculation of blood flow must take hematocrit into account (3). Because the [red cell]

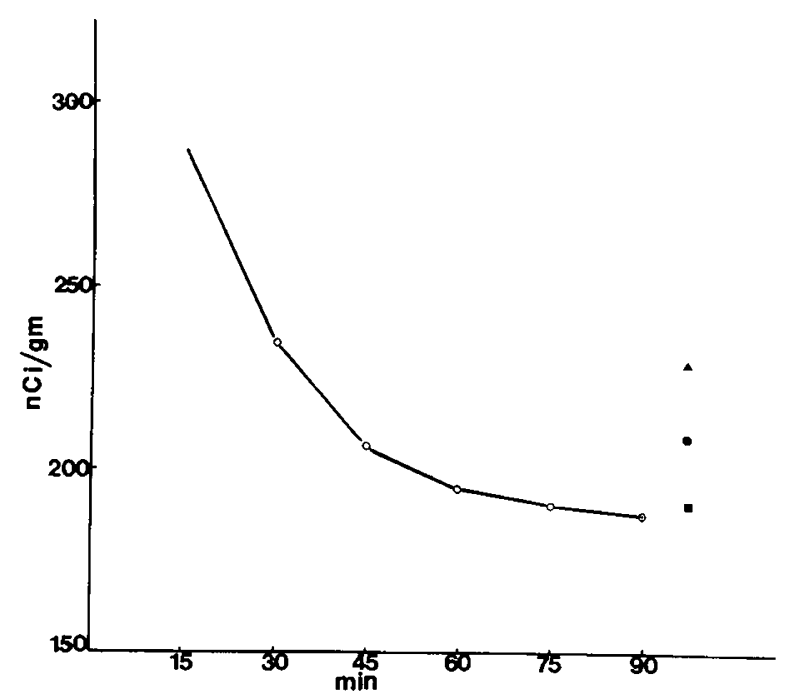

Fig. 1. [Brain tissue]:[plasma] partition coefficient as determined in one experiment. Concentration of $\left[{ }^{14} \mathrm{C}\right]-\mathrm{IAP}(\mathrm{nCi} / \mathrm{g})$ is seen on ordinate. Time (min) is displayed on abscissa. Tracer $\left(50 \mu \mathrm{Ci}\left[{ }^{14} \mathrm{C}\right]\right.$-iodoantipyrine) is administered at time 0 . Curve shows falling plasma tracer concentration with time $(\bigcirc)$. Tissue concentration of tracer was determined by autoradiography (see "Materials and Methods"). $\Delta$ represents concentration of tracer in cortex, caudate, and thalamus at $90 \mathrm{~min}$ (calculated $\lambda=1.22$ ); represents concentration of tracer in centrum semiovale (calculated $\lambda$ $=1.02$ ); and represents concentration of tracer in GM (calculated $\lambda=$ $1.12)$. 

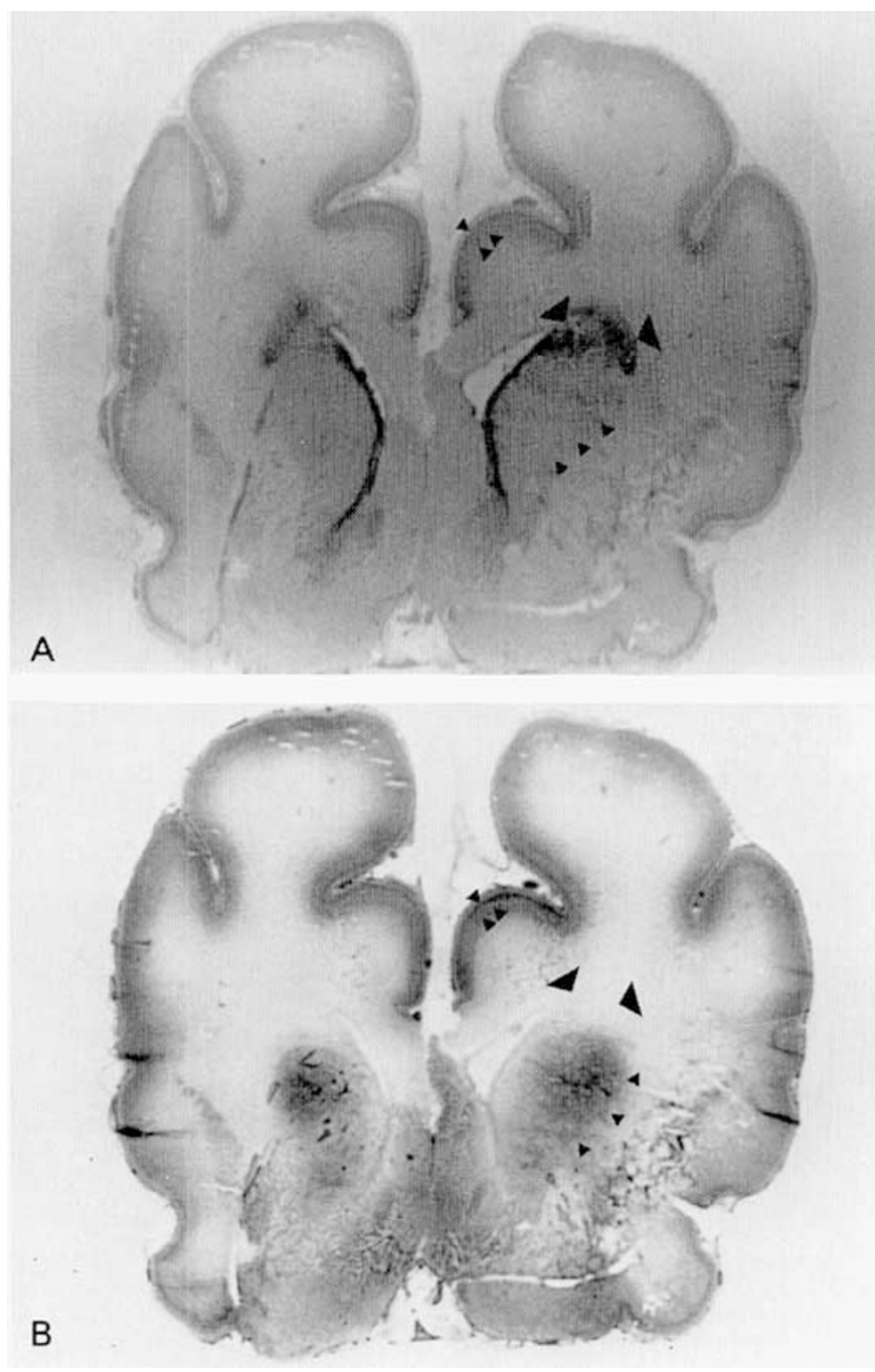

Fig. $2 a .20-\mu$ frozen section through the head of caudate nucleus (triple arrows) stained with hemotoxylin-eosin. The frontal cortex can be seen to consist of an outermost zone of compact neurons (single arrow) and an innermost zone of more loosely spaced neurons (double arrows). The germinal matrix (large arrows) is best seen along the anterior-lateral aspect of the lateral ventricle, overlying the caudate nucleus.

Fig. $2 b$. Autoradiograph from an adjacent section to the one shown in 1a. The gradient of isotope uptake in cortex can be seen (single arrow indicates dense outer cortical zone; double arrow indicates less dense inner zone). The germinal matrix (large arrows) has taken up little isotope, which makes the border between the germinal matrix and centrum ovale essentially indistinguishable on the autoradiograph. The border between the caudate nucleus (triple arrows) and germinal matrix is sharp.

:[plasma] partition coefficient was essentially 1.0 , we could ignore hematocrit in the calculation of blood flow. Second, because the iodoantipyrine distributed equally between red cells and plasma, we were able to use plasma, rather than whole blood, tracer concentration in the calculations of blood flow.

The [brain tissue]:[blood] partition coefficient was found to be slightly higher in grey matter than in white matter. This difference could be interpreted as indicating that full equilibrium had not been achieved. We think this explanation is unlikely because plasma tracer concentration was essentially constant for the final 30-45 min of each $\lambda$ experiment (Fig. 1). We calculated blood flow to all areas using a [tissue]:[blood] partition coefficient of 1.1. The change in the calculated blood flow to white matter would be small $(0.14 \%)$ if a [tissue]:[blood] partition coefficient of 1.0 were used. If white matter blood flow remains below $50 \mathrm{ml} / 100 \mathrm{~g} / \mathrm{min}$,
Table 1. Regional cerebral blood flow values to selected brain regions. Data is expressed as mean \pm S.E. $(n=5)$.

\begin{tabular}{lc}
\multicolumn{1}{c}{ Tissue } & $\begin{array}{c}\text { Blood flow } \\
(\mathrm{ml} / 100 \mathrm{~g} / \mathrm{min})\end{array}$ \\
\hline Grey matter & \\
Frontal cortex & $59 \pm 9$ \\
Parietal cortex & $59 \pm 9$ \\
Occipital cortex & $54 \pm 10$ \\
Caudate & $45 \pm 6$ \\
Amygdala & $61 \pm 10$ \\
Thalamus & \\
$\quad$ N. ventralis lateralis & $90 \pm 7$ \\
$\quad$ Anterior nuclear group & $81 \pm 12$ \\
Hypothalamus & $67 \pm 10$ \\
Hippocampus & $63 \pm 12$ \\
Oculomotor N. & $91 \pm 10$ \\
Superior colliculus & $43 \pm 10$ \\
Inferior colliculus & $49 \pm 7$ \\
Inferior olive & $124 \pm 25$ \\
Cerebellum & \\
$\quad$ Cortex & $43 \pm 8$ \\
$\quad$ Deep nuclei & $66 \pm 10$ \\
Pons reticular formation & $89 \pm 20$ \\
White matter & $7 \pm 1$ \\
Frontal & $6 \pm 1$ \\
Occipital & $16 \pm 3$ \\
Cerebellar hemisphere & $7 \pm 1$ \\
Germinal matrix & \\
\hline
\end{tabular}

the difference in calculated blood flow between a $\lambda$ of 1.0 and a $\lambda$ of 1.1 would remain below $1.19 \%$.

The rCBF values reported here are consistent with previous determinations of $\mathrm{rCBF}$ by other methodologies. Gregoire et al. (13), using a modification of the Kety-Schmidt technique, found that blood flow in the newborn pup was $48 \mathrm{ml} / 100 \mathrm{~g} / \mathrm{min}$. Venous samples were obtained from the superior sagittal sinus and reflected mostly parasagittal cortical flow, although some white matter flow was undoubtedly admixed (15). Kennedy et al. (17) studied rCBF in newborn dogs using $\left[{ }^{14} \mathrm{C}\right]$-antipyrine and quantitative autoradiography. Cortical blood flow was $33-39 \mathrm{ml} / 100$ $\mathrm{g} / \mathrm{min}$, thalamic flow $36-53 \mathrm{ml} / 100 \mathrm{~g} / \mathrm{min}$ and flow to brain stem nuclei $42-58 \mathrm{ml} / 100 \mathrm{~g} / \mathrm{min}$; blood flow to centrum semiovale was $7 \mathrm{ml} / 100 \mathrm{~g} / \mathrm{min}$. Subsequent studies in the adult rat established that antipyrine is diffusion limited and underestimates blood flow as determined with iodoantipyrine by as much as $50 \%$ (6). Thus, our regional cerebral flows are consistent with Kennedy's determinations when his values are corrected for the diffusion limitation of antipyrine. Iodoantipyrine has been shown to accurately measure regional blood flow when compared with trifluoroiodomethane $(30)$ or with a microsphere technique (31). Using a microsphere technique Goddard et al. $(10,11)$ have reported rCBF values for newborn beagles that are lower than ours; however, their results are not directly comparable with ours because their animals were anesthetized with methohexital [barbiturate anesthesia is known to decrease cerebral blood flow (19)] and because of the differences in spatial resolution between quantitative autoradiography and the direct tissue sampling used in the microsphere technique.

In our experiments, measurements of blood flow to the GM are reported for the first time. The germinal matrix is a densely cellular region with a high proliferative rate. Because it has been assumed that this structure has a high metabolic rate and because regional metabolism and blood flow are tightly coupled in the mature venous system (32), it was assumed that the GM received high blood flow $(16,25,34)$. This assumption seemed to be confirmed by the presence of prominent vascular spaces within GM seen with routine histology and in injected specimens (14, 25). Contrary to our expectation, we found baseline GM blood flow to be low, as low as flow in the centrum semiovale. This low 
flow stood in striking contrast to the much higher flows seen in every other densely cellular region of the brain.

Low blood flow to the GM is consistent with the proposal of Takashima and Tanaka (33) that the GM is at the end site of the penetrating thalamostriate arteries and that the portion of GM near the striae terminalis is a watershed zone between the thalamic and striate arteries; however, low GM blood flow seems inconsistent with the anatomical studies which show a prominent vascular bed in the GM of the human (14), rhesus monkey (21), and dog (28). At the present time, we have insufficient knowledge to totally resolve this inconsistency. It is possible that the prominent vascular bed was necessary earlier in gestation but is no longer required by $12 \mathrm{~h}$ postnatal age. If so, these vessels could be undergoing involution and thus be more fragile than vessels elsewhere in the brain. Alternatively, many of these vessels may be arteriovenous shunts through which the blood flow tracer could not exchange with tissue. For whatever reason however, our results combined with the anatomic studies noted above imply that the GM has a low "effective" blood flow and a relatively high vascular volume.

Our animals were hyperoxic (mean $\mathrm{PO}_{2}, 149 \mathrm{~mm} \mathrm{Hg}$ ). More extreme hyperoxia (mean $\mathrm{PO}_{2}, 348 \mathrm{~mm} \mathrm{Hg}$ ) has been shown previously to reduce $\mathrm{rCBF}$ in the newborn beagle puppy by $20-30 \%$ (17). It is possible that the regulation of $\mathrm{CBF}$ to the germinal matrix is more sensitive to hyperoxia than that to other brain areas, thus accounting in part for the low GM blood flow seen in our animals. If so, hypoxia could be a potent cause of shunting blood flow to the GM. Studies designed to address these possibilities are now in progress in our laboratory.

The assumption that the GM receives high blood flow has been an important aspect of current hypotheses concerning the pathogenesis of IVH $(16,34)$. Multiple physiologic factors have been proposed as major or minor contributors to IVH, includng anoxia (16), increased arterial blood pressure and increased cerebral blood flow (23), decreased arterial pressure and ischemic brain injury (7), increased cerebral venous pressure (4), hyperosmolality (27), and coagulation defects (12). The most consistent feature of the hemorrhage is that it originates within the substance of the GM. The risk of IVH as a function of gestational age correlates closely with the total extent of $\operatorname{GM}(1,26)$. After 34 wks of gestational age, involution of GM has occurred and IVH is rare. When hemorrhage does occur in these more mature infants, it originates from choroid plexus rather than brain parenchyma (5). Moreover, the site of hemorrhage in the immature infant is influenced by the local extent of the GM. Before 29 wk gestation, the parenchymal hemorrhage usually arises along the body of the lateral ventricle $(20,25)$. After $29 \mathrm{wk}$, the $\mathrm{GM}$ has involuted considerably along its posterior extent; almost all parenchymal hemorrhage after $29 \mathrm{wk}$ arises at the level of the head of the caudate nucleus where the GM remains plush $(20,25)$. The constant localization of the parenchymal hemorrhage in the GM has been attributed to the presumed hemodynamic properties of this structure, namely that baseline blood flow to GM is high and that increases in total brain flow would disproportionately increase GM blood flow $(16,34)$. This shunting of blood flow to GM would eventually result in vascular rupture and hemorrhage.

One cannot automatically equate regional blood flow values determined in the newborn dog to those which are present in the premature human; however, there is good reason to assume that the GM of the beagle pup is physiologically similar to the GM of the premature infant. The GM of the full term pup is similar histologically to the GM of a 30-32 wk gestation infant (8). Moreover, acute hypercarbia (8), acute hypertension (9), and volume expansion after hemorrhagic hypotension (11) in the pup result in germinal matrix and intraventricular hemorrhage which is similar pathologically to the human lesion.

Our results contradict the assumption that the GM receives a high baseline blood flow. Thus, it is unlikely that a disproportionate increase in GM blood flow would automatically result from an increase in total brain blood flow. It is likely that conditions which increase total brain blood flow, e.g., hypertension (10) and volume expansion following hemorrhagic hypotension (11), would also increase GM blood flow. But unless the increase in GM blood flow is of larger magnitude than the increases to other brain areas, excessive blood flow alone cannot explain the consistent localization of hemorrhage to the GM. Further studies are in progress in our laboratory to evaluate the effects of arterial hypertension and asphyxia on GM blood flow.

\section{REFERENCES AND NOTES}

1. Ahmann, P. A., Lazarra, A., Dykes, F. D., Brann, A. W. S., and Schwartz, J. F.: Intraventricular hemorrhage in the high-risk preterm infant: incidence and outcome. Ann. Neurol., 7: 118 (1980).

2. Blasberg. R. G., Groothius, D., and Molnar, P.: Application of quantitative autoradiographic measurements in experimental brain tumor models. Seminars in Neurology, 1: 203 (1981).

3. Carlin, R., and Chien. S.: Partition of xenon and iodoantipyrine among erythrocytes, plasma, and myocardium. Circ. Res., 40: 497 (1977).

4. Cole, V. A., Durbin, G. M., Olaffson, A., Reynolds, E. O. R., Rivers, R. P. A., and Smith, J. F.: Pathogenesis of intraventricular haemorrhage in newborn infants. Arch. Dis. Child., 49: 722 (1974).

5. Donat, J. F., Okazaki, H., Kleinberg, F., and Reagan, T. J.: Intraventricular hemorrhage in full-term and premature infants. Mayo Clin. Proc., 53: 437 (1978).

6. Eckman. W. W., Phair, R. D., Fenstermacher, J. D., Patlak, C. S., Kennedy, C., and Sokoloff, L.: Permeability limitation in estimation of local brain blood flow with $\left[{ }^{14} \mathrm{C}\right]$ antipyrine. Am. J. Physiol., 228: 215 (1975).

7. Fujimura, M., Salisbury, D. M., Robinson, R. O., Howat, P., Emerson, P. M., Keeling, J. W., and Tizard, J. P. M.: Clinical events relating to intraventricular haemorrhage in the newborn. Arch. Dis. Child., 64: 409 (1979).

8. Goddard, J., Lewis, R. M., Alcala, H., and Zeller, R. S.: Intraventricular Hemorrhage - an animal model. Biol. Neonate, 37: 39 (1980).

9. Goddard, J., Lewis, R. M., Armstrong, D. L., and Zeller, R. S.: Moderate, rapidly induced hypertension as a cause of intraventricular hemorrhage in the newborn beagle model. J. Pediatr.. 96: 1057 (1980).

10. Goddard, J., Lewis, R. M., Michael, L. H., and Armstrong, D. L.: Preliminary studies of regional cerebral blood flow in hypovolemic and hypertensive newborn beagle pups (Abstract). Ann. Neurol., 8: 224 (1980).

11. Goddard, J., Armstrong, D. L., and Michael, H. M.: Regional cerebral blood flow in the beagle model of intraventricular hemorrhage during volume expansion following acute hemorrhagic hypotension. (Abstract) Ann. Neurol., 10: 309 (1981).

12. Gray, O. P., Ackerman, A., and Fraser, A. J.: Intracranial haemorrhage and clotting defects in low birth-weight infants. Lancet, $l: 545$ (1968).

13. Gregoire, N. M., Gjedde, A., Plum, F., and Duffy, T. E.: Cerebral blood flow and cerebral metabolic rates for oxygen, glucose, and ketone bodies in newborn dogs. J. Neurochem., 30: 63 (1978).

14. Hambleton, G. and Wigglesworth, J. S.: Origin of intraventricular hemorrhage in the preterm infant. Arch. Dis. Child., 5l: 651 (1976).

15. Hegedus, S. A. and Shackelford, R. T.: A comparative-anatomical study of the cranio-cervical venous systems in mammals, with special reference to the dog: relationship of anatomy to measurements of cerebral blood flow. Am. J. Anat.. 116: 375 (1965).

16. Hill, A. and Volpe, J. J.: Seizures, hypoxic-ischemic brain injury, and intraventricular hemorrhage in the newborn. Ann. Neurol., 10: 109 (1981).

17. Kennedy, C., Grave, G. D., and Jehle, J. W.: Effect of hyperoxia on the cerebral circulation of the newborn puppy. Pediatr. Res.. 5: 659 (1971).

18. Kety. S. S.: The theory and application of the exchange of inert gas at the lungs and tissues. Pharmacol. Rev., 3: I (1951).

19. Landau, W. M.. Freygang, W. H., Jr., Rowland, L. P., Sokoloff, L., and Kety, S. S.: The local circulation of the living brain: values in the unanesthetized and anesthetized cat. Trans. Am. Neurol. Assoc., 80: 125 (1955).

20. Leech, R. W. and Kohnen, P.: Subependymal and intraventricular hemorrhages in the newborn. Am. J. Path., 77: 465 (1977).

21. Lenn, N. J.: Germinal matrix in the normal rhesus monkey fetus: Light and electron microscopic observations. Ann. Neurol., 10: 283 (1981).

22. Lou. H. C., Lassen, N. A., and Friis-Hansen, B.: Impaired autoregulation of cerebral blood flow in the distressed newborn. J. Pediatr., 94: 118 (1979).

23. Lou, H. C., Lassen. N. A., and Friis-Hansen, B.: Is arterial hypertension crucial for the development of cerebral haemorrhage in premature infants? Lancet, 1 : 1215 (1979).

24. Mulligan, D. W. A.: Failure of autoregulation and intraventricular haemorrhage in preterm infants. Lancet, $1: 869$ (1980).

25. Pape, K. E. and Wigglesworth, J. S.: Haemorrhage, ischemia and the perinatal brain. (Philadelphia: J. B. Lippincott, 1979).

26. Papile, L. A., Burstein, J., Burstein, R., and Koffler, H.: Incidence and evolution of subependymal and intraventricular hemorrhage: a study of infants with birth weight less than 1500 grams. J. Pediatr., 92: 529 (1978).

27. Papile, L., Burstein. J., Burstein, R., Koffler, H., and Koops, B.: Relationship of intravenous sodium bicarbonate infusions and cerebral intraventricular hemorrhage. J. Pediatr., 93: 834 (1979).

28. Pasternak, J. F. and Vick, N. A.: unpublished observations.

29. Rahilly, P. M.: Effects of $2 \%$ carbon dioxide, $0.5 \%$ carbon dioxide, and $100 \%$ oxygen on cranial blood flow of the human neonate. Pediatrics, 66: 685 (1980). 
30. Sakurada, O., Kennedy, C., Jehle, J., Brown, J. D., Carbin, G. L., and Sokokoff, L.: Measurement of local cerebral blood flow with iodo $\left[{ }^{14} \mathrm{C}\right]$ antipyrine. Am. J. Physiol., 234: H59 (1978).

31. Schuier, F. J., Fedora, T., Jones, S. L., and Reivich, M.: Comparison of rCBF obtained by the microsphere method versus the C14-iodoantipyrine method. J. Cereb. Blood Flow Metab., I: 576 (1981).

32. Sokoloff, L.: Relationships among local functional activity, energy metabolism, and blood flow in the central nervous system. Federation Proc. 40: 2311 (1981)

33. Takashima, S. and Tanaka, K.: Microangiography and vascular permeability of the subependymal matrix in the premature infant. Can. J. Neurol. Sci., 5: 45 (1978).

34. Volpe, J. J.: Neonatal Intraventricular hemorrhage. N. Engl. J. Med., 304: 886 (1981).

Copyright $(C) 1982$ International Pediatric Research Foundation, Inc

003 I-3998/82/1606-0499\$02.00/0
35. Youken, D., Reivich, M., Delivoria-Papadopoulos. M., and Obrist, W. D.: Regional cerebral blood flow in high risk neonates: technique and preliminary results. (Abstract) Ann. Neurol., 8: 226 (1980).

36. Presented in part at the 10th Annual Meeting of the Child Neurology Society, Minneapolis, MN, October, 1981.

37. Requests for reprints should be addressed to: Joseph F. Pasternak, Division of Pediatric Neurology, Evanston Hospital, 2650 Ridge Avenue, Evanston, Illinois 60201 .

38. This research was supported in part by a grant from Pediatric Research and Medicine, Highland Park, Illinois.

39. Received for publication November 24, 1981.

40. Accepted for publication March 15, 1982.

Printed in U.S.A. 